\title{
Analgesic effects of a capacitive-resistive monopolar radiofrequency in patients with myofascial chronic neck pain: a pilot randomized controlled trial
}

\author{
(D)Isabel Maria Alguacil-Diego ${ }^{1}$ \\ (iD) Josue Fernández-Carnero 1,2 \\ (iD) Sofía Laguarta-Val ${ }^{1}$ \\ Doberto Cano-de-la-Cuerda ${ }^{1}$ \\ (iD César Calvo-Lobo ${ }^{3}$ \\ (iD) Rosa Martínez-Piédrola ${ }^{1}$ \\ (iD) Laura Cristina Luna-Oliva ${ }^{1}$ \\ (iD Francisco Molina-Rueda ${ }^{1}$
} 1. Department of Physical Therapy, Occupational Therapy, Rehabilitation, and Physical Medicine. Rey Juan Carlos University, Madrid, Spain
2. Hospital La Paz Institute for Health Research, IdiPAZ, Madrid, Spain

3. Nursing and Physical Therapy Department, Faculty of Health Sciences, Universidad de León, Ponferrada, León, Spain

http://dx.doi.org/10.1590/1806-9282.65.2.156

\section{SUMMARY}

BACKGROUND: To date, there is a lack of prior studies on the use of capacitive resistive monopolar radiofrequency (RF) to treat neck pain. The objective of this study was to investigate the immediate effect of capacitive resistive monopolar radiofrequency (RF=448 $\mathrm{kHz}$ ), in comparison with a placebo, on (1) reducing neck pain intensity at myofascial trigger points $(M \operatorname{Tr} P)$, (2) decreasing neck disability and (3) improving cervical range of motion (CROM).

METHODS: A randomized, double-blind, placebo-controlled trial (NCT02353195) was carried out. Patients with myofascial chronic neck pain ( $N=24)$ with active MTrP in one upper trapezius muscle were randomly divided into two groups: a radio-frequency group, which received eight sessions of a monopolar capacitive resistive radio-frequency application over the upper trapezius muscle, and a placebo group (PG), which received eight sessions of placebo radio-frequency over the same muscle. Visual analog scale (VAS), CROM and Neck Disability Index (NDI) were evaluated after the first session and after the eight sessions.

RESULTS: The Wilcoxon test for VAS showed statistically significant differences between baseline, immediately after the first session and after eight sessions ( $p<.001)$. No significant differences for PG were found. No differences were observed between groups. NDI improved in both groups after eight sessions, but no differences were found between groups $(p<.05)$. ANOVA for time factor showed statistically significant changes in the right cervical rotation in both groups ( $F=4.112 ; p=.026)$ after eight sessions.

CONCLUSIONS: Even though there were no differences between both groups, the monopolar capacitive, resistive RF could have a potential effect on pain intensity.

KEYWORDS: Myofascial pain syndromes. Neck pain. Range of motion, articular. Catheter ablation/methods.

DATE OF SUBMISSION: 07-Apr-2018

DATE OF ACCEPTANCE: 22-Apr-2018

CORRESPONDING AUTHOR: Roberto Cano-de-la-Cuerda

Department of Physical Therapy, Occupational Therapy, Rehabilitation, and Physical Medicine

Rey Juan Carlos University Alcorcón, 28922, Madrid, Spain

Telephone: 0034-914888674

E-mail: roberto.cano@urjc.es

CORRESPONDING AUTHOR: César Calvo-Lobo

Av. Astorga, s/n, Ponferrada, 24401, León, Spain

Telephone: 605811782 - Fax: 605

E-mail: ccall@unileon.es 


\section{LIST OF ABBREVIATIONS}

- Cervical range of motion (CROM)

- Myofascial pain (MP)

- Myofascial trigger points (MTrP)

- Monopolar capacitive resistive radio-frequency (MCRRF)

- Neck disability Index (NDI)

- Neck pain intensity (NPI)

- Placebo group (PG)

- Radio-frequency (RF)

- Radio-frequency group (RFG)

- Visual analog scale (VAS)

\section{INTRODUCTION}

Neck pain is currently a major health problem in developed countries ${ }^{1}$ and is the leading cause of disability worldwide ${ }^{2}$. Neck pain can lead to negative coping strategies, disability and reduced quality of life, which may, in turn, lead to episodes of depression or anxiety ${ }^{3}$. It affects approximately $50 \%$ of people at some point in their lifetimes ${ }^{4}$, and its social and economic impact is considerable ${ }^{5}$. Neck pain tends to be chronic, and its etiology is rarely known; therefore, it is typically classified as nonspecific neck pain or mechanical neck pain ${ }^{6}$. In contrast to this disease entity, myofascial pain (MP) is considered a common cause of neck pain. MP is characterized, upon examination, by the presence of myofascial trigger points (MTrP) in skeletal muscles, which consists of hyperirritable areas located in a palpable, taut band of muscle fibers ${ }^{7,8}$.

The effectiveness and safety of combined treatments including both conventional and complementary alternative medical treatment modalities have not been fully established. Various treatment modalities are available for myofascial chronic neck pain including electrotherapy, education, injection therapy, acupuncture, and dry needling interventions ${ }^{9,10}$.

Patients with neck pain tend to concurrently utilize both conventional treatment and complementary alternative treatment in the hope of achieving more positive effects with a better safety profile. These alternative therapeutic modalities include radio-frequency (RF). RF energy is currently the most commonly used energy source to generate therapeutic levels of heat. Supraphysiologic temperature has been used medically to produce structural and biologic responses in tissue. Although its most common use is as an electrocautery tool, it is possible to use $\mathrm{RF}$ in a nonabrasive form by controlling the heating of target tissues to achieve structural and biologic therapeutic effects ${ }^{11-13}$. This constitutes a noninvasive Monopolar Capacitive Resistive Radio-frequency (448 kHz) (MCRRF).

It has been described that the effect of RF on muscle is mediated by the impact on myogenic precursor cells. RF also induces an inflammatory and antinociceptive response ${ }^{14}$. This is possible due to the production of a reverse thermal gradient and capacitive coupling of the energy into a volume of tissue $^{12,13}$. Molecular and cellular mechanisms other than thermal ones have recently been proposed for tissue repair through the local promotion of mesenchymal cells ${ }^{15}$.

A pilot study could evaluate the feasibility of recruitment, randomization, retention, assessment procedures, new methods, and implementation of a novel intervention. This pilot study aimed to evaluate the feasibility of MCRRF for the treatment of myofascial chronic neck pain immediately after one session and after eight sessions. To our knowledge, this is the first study that has investigated the MCRRF in myofascial chronic neck pain.

\section{METHODS}

Participants

The participants were recruited from the Rehabilitation Area of the Rey Juan Carlos University between October 2013 and June 2014. The inclusion criteria defined patients aged between 18 and 60 years with myofascial chronic neck pain. The area of neck pain was defined as the cervical region, possibly with referred or radiating pain into the occiput, nuchal muscles, shoulders, and upper limbs. Symptoms had to have been present for at least six months. At least one active MTrP in one upper trapezius muscle had to be present. For bilateral neck pain, the most painful side was designated for treatment ${ }^{9,10}$. All of the procedures used in this study were planned according to the ethical principles of the Declaration of Helsinki and were approved by the Ethics Committee of the Rey Juan Carlos University (15/2013), and registered in Clinical Trials.gov (NCTO2353195).

Exclusion criteria included severe disorders of the cervical spine, such as spinal stenosis, disk prolapse, postoperative conditions of the neck and shoulder areas, history of severe trauma, whiplash, spasmod- 
ic torticollis, instability, migraine, peripheral nerve entrapment, fibromyalgia, shoulder diseases, inflammatory rheumatic diseases, severe psychiatric illness, and pregnancy ${ }^{9,10}$.

Twenty-six patients with chronic nonspecific neck pain were initially recruited.

\section{Active MTrP diagnosis criteria}

An active MTrP was selected in one upper trapezius muscle following the Simons et al. ${ }^{16}$ criteria. The presence of a nodule in a taut band of skeletal muscle, plus the patient's pain recognition under stimulation and the range of motion limitation at full stretch were necessary to diagnose an active MTrP. In such case, there were more than 1 active MTrP in the upper trapezius muscle; the most hyperalgesic MTrP (which produced more pain intensity under the same pressure of stimulation) was selected in order to be treated ${ }^{17,18}$. In addition, the examiners presented the experience and specialization necessary to achieve a good inter-examiner agreement (Kappa coefficient; $\kappa=0.63$ ) in order to diagnose an active MTrP in the upper trapezius muscle ${ }^{19}$.

\section{Study design}

This pilot study was a prospective, randomized, double-blind, and placebo-controlled trial to determine the feasibility of MCRRF $(448 \mathrm{kHz})$ in patients with myofascial chronic neck pain. The Consolidated Standards of Reporting Trials (CONSORT) ${ }^{20}$ guidelines were implemented in this paper.

The findings of this pilot study could guide in the design and implementation of a larger scale efficacy study. Those components that are deemed infeasible or unsatisfactory will be modified in the subsequent trial or removed altogether, i.e., side effects, number of dropouts, electrical dose and changes in outcome measures.

Each subject recruited in the study was randomly assigned to the placebo (PG) or radio-frequency group (RFG) using computer-generated random-sequence numbers, with Graph Pad software (Graphpad Software, Inc., La Jolla, CA 92037 USA), and a table was created beforehand to perform the study with a concealed assignment. The randomization process was blocked. The participants were blinded to the treatment. The allocation was concealed, the patients received the assigned intervention in opaque envelopes, the therapist who applied the interventions was blinded to the assessment outcomes until the end of the entire data collection, and drop-out rates were recorded after randomization.

A questionnaire was compiled to obtain baseline information about the participants' demographics and ages, and patients were given a body chart to mark the location of their pain and answered a questionnaire regarding their pain.

Evaluation of pain intensity and cervical range of movement (CROM) were carried out before the start of treatment and after the first and eighth treatment sessions. The neck disability was evaluated before treatment and immediately after eight sessions, and the evaluation sessions were always scheduled at the same time of day. This was a pilot study.

\section{Intervention}

A INDIBA ${ }^{\circledR}$ activ 902 equipment was used for MCRRF (448 kHz). A 35-mm diameter CAP and 30mm diameter RES movable electrode were used on the affected side, and a planar electrode was used as a return electrode on the abdomen. The application was administered in the following manner: cream was applied to the site with the severest pain and its adjacent area (near to the most hyperalgesic MTrP in the upper trapezius muscle), and the electrical dose was increased by moving the movable electrode within the patient's tolerance level, while monitoring the skin temperature tolerable to the patient.

The PG was treated with the same device in a nonfunctional application (no energy source). The participants were informed that the system did not generate heat.

Therapy was conducted for 12 minutes, two times per week over four weeks (eight sessions in total). Therapeutic efficacy was evaluated regarding improvement in pretreatment symptoms compared to post-treatment symptoms and between-group comparisons. No other therapies that might affect the judgment of therapeutic efficacy were conducted during the treatment. No medication was taken during this study. An experienced therapist administered the treatments.

A blind-to-the-treatment-allocation evaluator recorded the visual analog scale (VAS), CROM and neck disability Index (NDI) measurements pre- and post-treatment.

\section{Outcome measures}

Pain intensity was measured using a 100-mm VAS. This scale consists of a 100-mm horizontal 
line with pain descriptors ranging from "no pain" marked on the left side to "the worst pain imaginable" on the right side. The perceived pain level of the patients was measured at rest, by marking the VAS with a perpendicular line. This is a valid method to measure pain level21, and psychometric properties of the VAS have been reported widely ${ }^{22}$. The minimal important difference of the VAS is based on detecting an 8.6-mm difference (based on a previous study for a score $<40 \mathrm{~mm}$ with a pain onset of greater than 12 weeks) immediately after treatment ${ }^{23}$. The VAS has been documented in previous studies as having good reliability and validity ${ }^{24,25}$.

The NDI was used. NDI is a self-reporting questionnaire used to determine how neck pain affects a patient's daily life. It consists of ten questions in the following domains: Pain Intensity, Personal Care, Lifting, Reading, Headaches, Concentration, Work, Driving, Sleeping, and Recreation. Each question contains six response options, scored from 0 (no disability) to 5 (complete disability). All section scores are then totaled. Scoring is reported on a $0-50$ scale ( 0 being the best possible score and 50 the worst). The NDI has good construct validity. The NDI is seen as a valid tool to measure neck pain and disabilities in patients with neck pain due to acute or chronic conditions, as well as in patients suffering from musculoskeletal dysfunctions, according to its adequate psychometric properties for test-retest reliability (intraclass correlation coefficient of 0.50) and minimum clinically important difference (19-percentage points) $)^{26-28}$.

CROM was measured with a CROM device (Performance Attainment Associates, Roseville, MN) ${ }^{29}$. The CROM device was placed on the subject's head, and a magnetic collar, also part of the CROM device, was placed on the shoulders to take into account any rotation of the trunk. The collar was always placed in the same position to the magnetic pole; the chair on which the subjects were sitting was kept in the same position for all data collection. The initial position of the head was set to neutral at the zero mark of the inclinometer for flexion, extension and both side flexion. For rotation, the dial was set to zero with the head in the neutral position. When the motion was performed in one direction, the final position was read and recorded for each trial. Subjects moved their heads back to the initial position once the reading was finished. Three trials were executed consecutively in each direction, and the average of the three trials was computed for the analysis. This is a reliable method of measurement ${ }^{29}$, providing intra-meter reliability ranging from 0.70 to 0.90 and inter-meter reliability from 0.80 to 0.87 .

\section{Data analysis}

The statistical analysis was carried out using the SPSS statistical software system (SPSS Inc., Chicago, IL; version 20.0). Normal distribution for the CROM variable was found using the Shapiro-Wilk test, except for VAS and NDI.

The independent t-test and one-way ANOVA were used for analysis of CROM, as well as the subjects' socio-demographic data (age, and pain duration), comparing the baseline data for the two groups. Analyses were performed according to the intention-to-treat principle.

For the CROM variable, two-way repeated measures within-between ANOVA interaction factors were performed; the factors analyzed were group (RFG vs. PG), time (Pre-, Post- and Post-eight sessions), and group $\mathrm{x}$ time interaction. Post hoc analysis with Bonferroni corrections was performed in the case of significant ANOVA findings for multiple comparisons between variables.

We used nonparametric statistics for VAS and NDI variables, which were abnormally distributed. Descriptive statistics were used to summarize data, including means and SDs, medians and interquartile ranges (IQR) for continuous data. For comparisons across and between-groups, we used the $U$ Mann-Whitney. The Friedman test was used to analyze the change from the intra-group results, and the Wilcoxon signed-rank test was used for post-hoc intra-group comparisons. Statistical tests were interpreted at the $5 \%$ significance level.

\section{RESULTS}

Twenty-six patients with myofascial chronic neck pain in the trapezius muscle were screened for possible eligibility criteria, and twenty-four patients successfully completed the study protocol, of which 14 were randomly assigned to the RFG and completed the study protocol (four male, 10 female; mean age $\pm \mathrm{SD}, 31.8 \pm 12.4 \mathrm{ys})$ and 10 were assigned to the PG (six male, four female; mean age \pm SD, $42.1 \pm 12.6$ ys). Figure 1 shows the diagram of recruitment and dropouts. Demographic and clinical characteristics at the beginning of the study are summarized in Ta- 
ble 1. There were no significant differences between the two groups regarding demographic and clinical characteristics at baseline. No adverse events were reported in this study.

\section{VAS score}

RFG presented statistically significant differences between pain intensity in baseline versus all measurement periods $(p<.001)$ but not PG. In comparisons between groups, no differences were found using the U Mann-Whitney test. The results for VAS are presented in Table 2.

\section{Neck disability outcomes}

NDI improved in both groups with statistically significant differences after receiving eight sessions of intervention $(p<.05)$. In comparisons between groups, no differences at eight sessions were found using the Mann-Whitney U test. The results for neck disability are presented in Table 2 .

\section{CROM outcomes}

Repeated ANOVA measures showed no effect for time in all cervical range of motions (Flexion $\mathrm{F}=2.47$; $p=.101 ;$ Extension $\mathrm{F}=.044 ; p=.957 ; \mathrm{hp}^{2}=.003 ;$ Right lateroflexion $\mathrm{F}=2.812 ; p=.076 ; \mathrm{hp}^{2}=.158$; Left lateroflexion $\mathrm{F}=1.472 ; p=.246 ; \mathrm{hp}^{2}=.089$; Left Rotation $\mathrm{F}$ $\left.=.713 ; p=.498 ; \mathrm{hp}^{2}=.045\right)$, except right rotation (right rotation $\left.\mathrm{F}=4.112 ; p=.026 ; \mathrm{hp}^{2}=.215\right)$; time $\mathrm{X}$ group interaction was not found (Flexion $\mathrm{F}=1.356 ; p=.273$; $\mathrm{hp}^{2}=.083 ;$ Extension $\mathrm{F}=.173 ; p=.842 ; \mathrm{hp}^{2}=.011 ;$ Right lateroflexion $\mathrm{F}=.198 ; p=.821 ; \mathrm{hp}^{2}=.013$; Left lateroflexion $\mathrm{F}=1.406 ; p=.261 ; \mathrm{h}^{2}=.086$; Right Rotation $\mathrm{F}=.066 ; p=.936 ; \mathrm{hp}^{2}=.004 ;$ Left Rotation $\mathrm{F}=.425 ; p$ $\left.=.658 ; \mathrm{hp}^{2}=.028\right)$. The comparison of the results for CROM within groups is presented in Table 3.

\section{DISCUSSION}

The purpose of this study was to evaluate MCRRF $(448 \mathrm{kHz})$ for the treatment of neck pain compared to a placebo intervention. Most studies that analyze the effects of RF in pain intensity have not included a placebo group. Therefore, the placebo effect of RF remains unexplored. The results obtained from this study suggest that RF could potentially be used to treat myofascial chronic neck pain in the trapezius muscle.

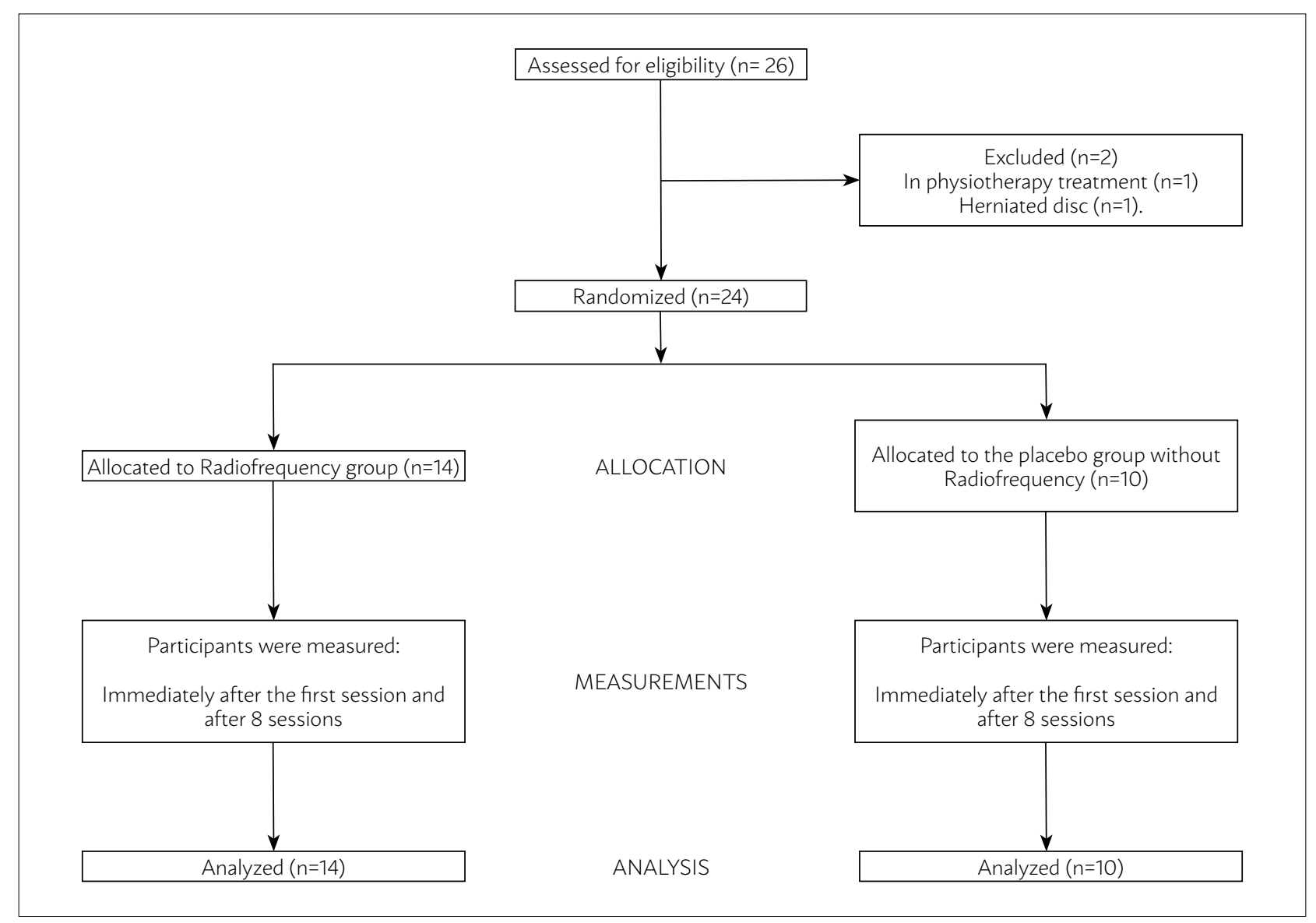

FIGURE 1: FLOW DIAGRAM OF THE STUDY 


\section{Neck pain intensity}

A significant improvement in pain intensity was observed in the RF group immediately after the first session and after receiving eight sessions.

The magnitude of change was clinically important in the RF group. It has been established that a reduction of $0.85 \mathrm{~cm}$ is a minimally detectable change ${ }^{23}$, and we initially found $2.9 \mathrm{~cm}$ and $4.4 \mathrm{~cm}$ after eight sessions on the visual analog scale. The short-term effects showed in this study are slightly less significant than the outcomes found by Llamas-Ramos et al. ${ }^{30}$ with a variation of between 4.3 and $5.3 \mathrm{~cm}$ immediately and at two weeks during follow-up post-treatment in which dry needling was applied over the trapezius muscle. Nevertheless, Mejuto-Vázquez et al. ${ }^{31}$ reported a change between $1.9 \mathrm{~cm}$ and $3.7 \mathrm{im}$ mediately and one-week post-treatment. However, our results are superior to Seo et al. ${ }^{32}$, which treated patients with mean electoral nerve stimulation and botulinum toxin A, although they followed up with the patients for 16 weeks.

Therefore, according to early clinical studies with RF, this technology could have the potential to become an effective therapy for neck pain. However, these differences were not significant between groups. Therefore, further trials should include other types of measures for outcomes in order to assess in-depth the RF effects on pain. In this sense, it could be interesting to include outcome measures such as clinical pressure-pain algometric measurements.

TABLE 1: BASELINE CHARACTERISTICS OF PATIENTS IN BOTH GROUPS

\begin{tabular}{l|l|l|l|l} 
& RFG $(n=14)$ & $P G(n=10)$ & Total $(n=24)$ & P value \\
\hline Age in years & $31.8 \pm 12.4$ & $42.1 \pm 12.6$ & $36.3 \pm 13.3$ & .06 \\
\hline Gender (female/male) & $10 / 4$ & $4 / 6$ & $14(58.3)$ & .12 \\
\hline Neck pain duration (months) & $13.35 \pm 11.39$ & $12.00 \pm 8.64$ & $12.79 \pm 10.15$ & .75 \\
\hline VAS_NPI (O-10 cm) & $4.7 \pm 1.8$ & $4.9 \pm 2.6$ & $4.5 \pm 2.03$ & .34 \\
\hline NDI & $10.5 \pm 4.6$ & $13.8 \pm 6.7$ & $12.45 \pm 5.59$ & .06 \\
\hline CROM FLEX & $45.57 \pm 13.63$ & $43.66 \pm 2.03$ & $44.90 \pm 12.74$ & .80 \\
\hline CROM EXT & $63.84 \pm 10.31$ & $48.77 \pm 12.50$ & $58.52 \pm 13.05$ & $.03^{*}$ \\
\hline CROM LAT FLEX RIGHT & $37.27 \pm 8.26$ & $34.00 \pm 4.71$ & $36.11 \pm 7.22$ & .76 \\
\hline CROM LAT FLEX LEFT & $40.51 \pm 6.82$ & $33.11 \pm 6.23$ & $37.90 \pm 7.38$ & .69 \\
\hline CROM ROT RIGHT & $59.75 \pm 13.39$ & $56.66 \pm 13.59$ & $58.66 \pm 13.12$ & .19 \\
\hline CROM ROT LEFT & $62.48 \pm 14.69$ & $55.33 \pm 18.10$ & $59.96 \pm 15.80$ & .10 \\
\hline
\end{tabular}

TABLE 2: NON-PARAMETRIC TESTS OF OUTCOME DATA COMPARISONS WITHIN GROUPS AND BETWEEN GROUNS

\begin{tabular}{|c|c|c|c|c|c|c|}
\hline \multirow{2}{*}{ Parameter } & \multirow[b]{2}{*}{ Group } & \multicolumn{3}{|c|}{ Median (first and third quartiles) } & \multirow{2}{*}{$\begin{array}{l}\text { Friedman } \\
\text { ANOVA }\end{array}$} & \multirow{2}{*}{$\begin{array}{l}\text { Wilcox onvalueue) } \\
\text { a) Pre vs. First session } \\
\text { b) Pre vs. Eight sessions } \\
\text { c) First session vs. Eight sessions }\end{array}$} \\
\hline & & Basele in & $\begin{array}{l}\text { Immediatel after } \\
\text { the first session }\end{array}$ & $\begin{array}{l}\text { Immediately after } \\
\text { eight sessions }\end{array}$ & & \\
\hline \multirow[t]{2}{*}{ VAS } & RFG & $4.9(2.8$ and 6.4$)$ & $2.0(1.0$ and 3.0$)$ & $0.5(0$ and 2.0$)$ & $P=.001^{\star}$ & $\begin{array}{l}\text { a) } P<.001^{\dagger} \\
\text { b) } P<.001^{\dagger} \\
\text { c) } P>.05\end{array}$ \\
\hline & $P G$ & $5.7(2.4$ and 7.0$)$ & $6.0(1.9$ and 7.1$)$ & 2.5 (1.1 and 5.5) & $P=>.05$ & $\begin{array}{l}\text { a) } P>.05 \\
\text { b) } P>.05 \\
\text { c) } P>.05\end{array}$ \\
\hline \multicolumn{2}{|c|}{ Mann-Whitney $U$ test } & $P=.318$ & $P=.168$ & $P=.104$ & & \\
\hline \multirow[t]{2}{*}{ NDI } & RFG & 10.0 (8.0 and 12.0) & - & $3.0(2.0$ and 9.0$)$ & $P<.05^{*}$ & b) $P<.05$ \\
\hline & $P G$ & 14.0 (10.3 and 20.5) & - & 7.0 (6.0 and 14.5) & $\mathrm{P}<.05^{\star}$ & b) $P<.05$ \\
\hline \multicolumn{2}{|c|}{ Mann-Whitney $U$ test } & $P=.060$ & - & $P=.254$ & & \\
\hline
\end{tabular}

Abbreviations: RFG= Radio-frequency group; PG=Placebo group; VAS=Visual Analogue Scale; NDI=Neck Disability Index.

Within groups analysis: ${ }^{\star} P<.05$ using Friedman ANOVA for $k$ repeated measures; ${ }^{\dagger} P<.05$ using Wilcoxon test for two related samples. Between groups comparisons: ${ }^{* \star} P<.05$ using Mann-Whitney U test 
TABLE 3: CERVICAL RANGE OF MOVEMENT, EXPRESSED IN DEGREES, OVETIMECOMPARISONSNW WITN HITHGROUPSNS

\begin{tabular}{l|l|l|l|l|l}
\multicolumn{2}{l|}{} & Baseline & $\begin{array}{l}\text { Immediately after } \\
\text { the first session }\end{array}$ & $\begin{array}{l}\text { Immediately after } \\
\text { eight sessions }\end{array}$ & $\begin{array}{l}\text { ANOVA } \\
\text { p-value }\end{array}$ \\
\hline Flexion & RFG & $45.5 \pm 13.6$ & $\begin{array}{l}52.4 \pm 10.8 \\
42.6 \pm 11.4\end{array}$ & $\begin{array}{l}58.0 \pm 10.6 \\
45.7 \pm 28.0\end{array}$ & $>.05$ \\
& PG & $43.6 \pm 12.0$ & $>05$ & $7.9 \pm 16.1$ \\
\hline Extension & RFG & $63.8 \pm 10.3$ & $64.6 \pm 11.8$ & 62.9 & $>.05$ \\
& PG & $48.7 \pm 12.5$ & $45.7 \pm 14.8$ & $48.0 \pm 14.0$ & $>.05$ \\
\hline Right & RFG & $37.2 \pm 8.2$ & $40.0 \pm 7.5$ & $44.4 \pm 12.2$ & $>.05$ \\
Lateroflexion & PG & $34.0 \pm 4.7$ & $35.2 \pm 6.4$ & $38.1 \pm 9.8$ & $>.05$ \\
\hline Left & RFG & $40.5 \pm 26.8$ & $43.2 \pm 8.2$ & $44.1 \pm 9.0$ & $>.05$ \\
Lateroflexion & PG & $33.1 \pm 6.2$ & $28.8 \pm 9.7$ & $34.9 \pm 15.5$ & $>.05$ \\
\hline Right & RFG & $59.7 \pm 13.3$ & $60.2 \pm 10.9$ & $67.8 \pm 9.8^{*} \dagger$ & $.03 *$ \\
Rotation & PG & $56.6 \pm 13.5$ & $54.8 \pm 12.2$ & $63.4 \pm 12.6^{*} \dagger$ & $.03^{*}$ \\
\hline Left & RFG & $62.4 \pm 14.6$ & $62.9 \pm 14.3$ & $63.5 \pm 13.3$ & $>.05$ \\
Rotation & PG & $55.3 \pm 18.1$ & $57.6 \pm 11.3$ & $62.9 \pm 15.0$ & $>.05$ \\
\hline
\end{tabular}

NOTE. Values are mean $\pm S D$. Abbreviations: $R F G=$ Radio-frequency group; $P G=P l a c e b o$ group

*Significantly lower than baseline ( $P<.05)$ using two-way repeated-measures ANOVA (Bonferroni adjustment)

$\dagger$ Reached minimal detectable change from pre-intervention $(P<0.05)$

\section{Neck disability}

Both groups decreased from the baseline after eight sessions, but no significant differences were found between groups. As far we know, there are no studies in which radio-frequency has been administered for this condition.

In our study, the RFG achieved a $40 \%$ improvement. These changes in neck disability did not exceed the minimal detectable change (7.5 points on the NDI) (28). We also observed a 30\% improvement in PG. This placebo effect could be a psychobiological phenomenon that may be attributable to different mechanisms, including the expectation of clinical improvement. Overall, the placebo effect appears to be an excellent model to understand how a complex mental activity, such as expectancy, interacts with different neuronal systems ${ }^{29}$.

\section{Cervical range of motion}

The administration of MCRRF and placebo did not show a significant improvement in CROM, except for right rotation, but no differences were found between groups. Cervical right rotation showed significant improvement of $8.1^{\circ}$ after the eight sessions in the $\mathrm{RF}$ group and $6.8^{\circ}$ in the placebo group. Cervical right rotation seems to improve $2^{\circ}$ more with RFG. The minimal detectable change of $6.1^{\circ}$ for right rotation was achieved in both groups, as stated previously ${ }^{29}$.

To the best of the authors' knowledge, this is the first time that MCRRF has been investigated on CROM as a treatment for myofascial neck pain, how- ever our results contradict those of previous studies, in which CROM improved after the administration of other therapies, such as trigger point dry needling $^{30,31}$ lidocaine injection ${ }^{30}$ and transcutaneous electrical nerve stimulation ${ }^{32-34}$.

The etiology of MTrP is unknown, but the cascade of mechanisms postulated by Simons describes three features involved in MTrP mechanisms, which are as follows: increased acetylcholine release in the motor endplate, a release of sensitizing substances and increase of the muscle fiber tension ${ }^{35,36}$. Considering the previous hypothesis, one plausible explanation for our results is that MCRRF could produce vasodilation due to the increased temperature, reverting local ischemia and hypoxia and decreasing the release of sensitizing substances and acetylcholine. RF induces the inflammatory cascade necessary to remove hemorrhage remnants and produce an antinociceptive response ${ }^{11}$. In our study, if there were more than 1 active MTrP, the most hyperalgesic active MTrP was selected to receive the intervention ${ }^{17,18}$. However, MCRRF would not reduce sarcomere shortening because the patients in our study did not improve in range of motion; however, they did improve in pain intensity.

\section{Study limitations}

The primary limitation of the study is the small sample size. Consequently, the results need to be interpreted with due caution. The statistical analysis has shown no differences between groups after the intervention. However, the differences were ob- 
served in the RFG. Further studies have to increase the sample size with the aim to increase statistical power. Second, in cases of bilateral neck pain, we only treated the more painful side, which may bias the results. In addition, the localization of the myofascial trigger points may change along the different sessions of treatment. Third, only one muscle was treated, the treatment of more muscles could modify the outcomes. Fourth, the lack of follow-up is another bias that must be taken into account in future studies. Fifth, we did not take into account psychological variables, and the emotional state may influence outcomes. Finally, the placebo procedure used in this study has not been previously validated, and the results should be interpreted with caution.

\section{CONCLUSION}

The Monopolar Capacitive Resistive Radio-frequency could have a potential effect on pain intensity. Neck pain intensity improved immediately after one and eight sessions of Monopolar Capacitive Resistive Radio-frequency (448 kHz) in RF group. Additionally, neck disability and right cervical rotation improved after eight sessions of $\mathrm{RF}$ and placebo. However, there were no statistical differences between RF and PG in the outcome measures.

The findings of this pilot study show that RF has no side effects and the electrical dose described in this manuscript could be taken into account in a large study. Further trials should include a follow-up assessment, additional outcome measures, and larger sample sizes.

\section{RESUMO}

ANTECEDENTES: Até a data, há uma falta de estudos prévios para tratar a dor no pescoço por radiofrequência (RF) monopolar capacitiva resistiva. O objetivo deste estudo foi investigar o efeito imediato da radiofrequência monopolar capacitiva resistiva $(R F=448 \mathrm{kHz})$ versus placebo em (1) redução da intensidade da dor no pescoço em pontos de gatilho miofascial (MTrP), (2) diminuição da incapacidade do pescoço e (3) melhorando a amplitude de movimento cervical (Crom).

MÉTODOS: Foi realizado um ensaio randomizado, duplo-cego, controlado por placebo (NCT02353795). Os pacientes com dor no pescoço crônica miofascial $(N=24)$ com MTrP ativo em um músculo trapézio superior foram divididos aleatoriamente em dois grupos: um grupo de radiofrequência, que recebeu oito sessões com uma aplicação de radiofrequência resistiva capacitiva monopolar sobre o músculo trapézio superior, e um grupo de placebo (PG), que recebeu oito sessões de radiofrequência de placebo no mesmo músculo. A escala analógica visual (VAS), Crom e Índice de incapacidade do pescoço (NDI) foram avaliadas após a primeira sessão e após as oito sessões.

RESULTADOS: O teste de Wilcoxon para VAS mostrou diferenças estatisticamente significativas entre a linha de base e imediatamente após a primeira sessão e após oito sessões $(p<0,001)$. Não foram encontradas diferenças significativas para PG. Não foram observadas diferenças entre os grupos. O NDI melhorou em ambos os grupos após oito sessões, mas não foram encontradas diferenças entre os grupos $(p<0,05)$. A Anova para o fator de tempo mostrou mudanças estatisticamente significativas na rotação direita cervical em ambos os grupos ( $F=4,12 ; p=0,26)$ após oito sessões.

CONCLUSÕES: Apesar de não haver diferenças entre os dois grupos, o RF resistivo capacitivo monopolar pode ter um efeito potencial sobre a intensidade da dor.

PALAVRAS-CHAVE: Síndromes da dor miofascial. Cervicalgia. Amplitude de movimento articular. Ablação por cateter/métodos.

\section{REFERENCES}

1. Punnett L, Wegman DH. Work-related musculoskeletal disorders: the epidemiologic evidence and the debate. J Electromyogr Kinesiol. 2004;14(1):13-23.

2. Marley I, Tully MA, Porter-Armstrong A, Bunting B, O'Hanlon I, McDonough SM. A systematic review of interventions aimed at increasing physical activity in adults with chronic musculoskeletal pain-protocol. Syst Rev. 2014;3:106

3. Smith BH, Elliott AM, Chambers WA, Smith WC, Hannaford PC, Penny K. The impact of chronic pain in the community. Fam Pract. 2001;18(3):292-9.

4. Fejer R, Kyvik KO, Hartvigsen J. The prevalence of neck pain in the world population: a systematic critical review of the literature. Eur Spine J. 2006;15(6):834-48.

5. Hogg-Johnson S, van der Velde G, Carroll LJ, Holm LW, Cassidy JD, Guzman J, et al. The burden and determinants of neck pain in the general population: results of the Bone and loint Decade 2000-2010 Task Force on Neck Pain and Its Associated Disorders. J Manipulative Physiol Ther. 2009;32(2 Suppl): S46-60.
6. Côté P, Cassidy JD, Carroll LJ, Kristman V. The annual incidence and course of neck pain in the general population: a population-based cohort study. Pain. 2004:112(3):267-73.

7. Travell JG, Simons DG. Dolor y disfunción miofascial. Barcelona: Editorial Médica Panamericana; 2004.

8. Fernández-de-las-Peñas C, Alonso-Blanco C, Miangolarra |C. Myofascial trigger points in subjects presenting with mechanical neck pain: a blinded, controlled study. Man Ther. 2007;12(1):29-33.

9. Seo BK, Lee JH, Kim PK, Baek YH, Jo DJ, Lee S. Bee venom acupuncture, NSAIDs or combined treatment for chronic neck pain: study protocol for a randomized, assessor-blind trial. Trials. 2014;15:132.

10. Lai $\mathrm{CH}$, Leung TK, Peng $\mathrm{CW}$, Chang $\mathrm{KH}$, Lai MI, Lai WF, et al. Effects of far-infrared irradiation on myofascial neck pain: a randomized, double-blind, placebo-controlled pilot study. J Altern Complement Med. 2014;20(2):123-9.

11. Whipple T, Villegas D. Thermal and electric energy fields by noninvasive monopolar capacitive-coupled radiofrequency: temperatures achieved and histological outcomes in tendons and ligaments. PM R. 2010;2(7):599606. 
12. Whipple TL. From mini-invasive to non-invasive treatment using monopolar radiofrequency: the next orthopaedic frontier. Orthop Clin North Am. 2009;40(4):531-5

13. Weber T, Kabelka B. Noninvasive monopolar capacitive-coupled radiofrequency for the treatment of pain associated with lateral elbow tendinopathies: 1-year follow-up. PM R. 2012;4(3):176-81.

14. Hayashi A. Getting athletes back in the game: a global view. AAOS Now. 2008;2(10):1-6.

15. Hernández-Bule ML, Paíno CL, Trillo MÁ, Úbeda A. Electric stimulation at $448 \mathrm{kHz}$ promotes proliferation of human mesenchymal stem cells. Cell Physiol Biochem. 2014;34(5):1741-55.

16. Simons DG, Travell JG, Simons LS. Dolor y disfunción miofascial: el manual de los puntos gatillo. Barcelona: Editorial Médica Panamericana; 2001.

17. Calvo-Lobo C, Pacheco-da-Costa S, Martínez-Martínez J, Rodríguez-Sanz D, Cuesta-Álvaro P, López-López D. Dry needling on the infraspinatus latent and active myofascial trigger points in older adults with nonspecific shoulder pain: a randomized clinical trial. J Geriatr Phys Ther. 2018;41(1):113.

18. Calvo-Lobo C, Pacheco-da-Costa S, Hita-Herranz E. Efficacy of deep dry needling on latent myofascial trigger points in older adults with nonspecific shoulder pain: a randomized, controlled clinical trial pilot study. J Geriatr Phys Ther. 2017;40(2):63-73.

19. Myburgh C, Lauridsen HH, Larsen AH, Hartvigsen J. Standardized manual palpation of myofascial trigger points in relation to neck/shoulder pain: the influence of clinical experience on inter-examiner reproducibility. Man Ther. 2011;16(2):136-40.

20. Moher D, Hopewell S, Schulz KF, Montori V, Gøtzsche PC, Devereaux PJ, et al. CONSORT 2010 explanation and elaboration: updated guidelines for reporting parallel group randomised trials. Int J Surg. 2012;10(1):28-55.

21. Kelly AM. Does the clinically significant difference in visual analog scale pain scores vary with gender, age, or cause of pain? Acad Emerg Med. 1998;5(11):1086-90.

22. Kahl C C). Visual analogue scale, numeric pain rating scale and the McGil pain questionnaire: an overview of psychometric properties. Phys Ther Rev. 2005;10(2):123-8.

23. Emshoff R, Bertram S, Emshoff I. Clinically important difference thresholds of the visual analog scale: a conceptual model for identifying meaningful intraindividual changes for pain intensity. Pain. 2011;152(10):2277-

24. Jensen MP, Turner JA, Romano JM, Fisher LD. Comparative reliability and validity of chronic pain intensity measures. Pain. 1999;83(2):157-62.
25. Katz J, Melzack R. Measurement of pain. Surg Clin North Am. 1999;79(2):231-52.

26. MacDermid JC, Walton DM, Avery S, Blanchard A, Etruw E, McAlpine C, et al. Measurement properties of the neck disability index: a systematic review. J Orthop Sports Phys Ther. 2009;39(5):400-17.

27. Cleland JA, Childs JD, Whitman JM. Psychometric properties of the Neck Disability Index and Numeric Pain Rating Scale in patients with mechanical neck pain. Arch Phys Med Rehabil. 2008;89(1):69-74.

28. Vernon H, Mior S. The Neck Disability Index: a study of reliability and validity. I Manipulative Physiol Ther. 1991;14(7):409-15.

29. Audette I, Dumas JP, Côté JN, De Serres S). Validity and between-day reliability of the cervical range of motion (CROM) device. J Orthop Sports Phys Ther. 2010;40(5):318-23.

30. Llamas-Ramos R, Pecos-Martín D, Gallego-Izquierdo T, Llamas-Ramos I, Plaza-Manzano G, Ortega-Santiago R, et al. Comparison of the shortterm outcomes between trigger point dry needling and trigger point manual therapy for the management of chronic mechanical neck pain: a randomized clinical trial. J Orthop Sports Phys Ther. 2014:44(11):852-61.

31. Mejuto-Vázquez MJ, Salom-Moreno J, Ortega-Santiago R, Truyols-Domínguez S, Fernández-de-Las-Peñas C. Short-term changes in neck pain, widespread pressure pain sensitivity, and cervical range of motion after the application of trigger point dry needling in patients with acute mechanical neck pain: a randomized clinical trial. | Orthop Sports Phys Ther. 2014;44(4):252-60.

32. Seo HG, Bang MS, Chung SG, Jung SH, Lee SU. Effect of electrical stimulation on botulinum toxin a therapy in patients with chronic myofascial pain syndrome: a 16-week randomized double-blinded study. Arch Phys Med Rehabil. 2013;94(3):412-8.

33. Hsueh TC, Cheng PT, Kuan TS, Hong CZ. The immediate effectiveness of electrical nerve stimulation and electrical muscle stimulation on myofascial trigger points. Am J Phys Med Rehabil. 1997;76(6):471-6.

34. Ardiç F, Sarhus M, Topuz O. Comparison of two different techniques of electrotherapy on myofascial pain. I Back Musculoskelet Rehabil. 2002;16(1):11-6

35. Gerwin RD, Dommerholt J, Shah JP. An expansion of Simons' integrated hypothesis of trigger point formation. Curr Pain Headache Rep. 2004;8(6):468-75.

36. Simons DG. Review of enigmatic MTrPs as a common cause of enigmatic musculoskeletal pain and dysfunction. Electromyogr Kinesiol. 2004;14(1):95-107. 
Regarding the article "Analgesic effects of a capacitive-resistive monopolar radiofrequency in patients with myofascial chronic neck pain: a pilot randomized controlled trial", with DOI number: http://dx.doi. org/10.1590/1806-9282.65.2.156 published in Journal of the Brazilian Medical Association, 2019;65;02, page 156

Names of the authors in the article changed from: Isabel Maria Alguacil Diego, Josué Fernández-Carnero , Sofia Laguarta Val, Roberto Cano-de-la-Cuerda, César Calvo-Lobo, Rosa Martínez Piédrola, Laura Cristina Luna Oliva, Francisco Molina Rueda

Now Read: Isabel Maria Alguacil-Diego, Josué Fernández-Carnero, Sofia Laguarta-Val, Roberto Cano-de-la-Cuerda, César Calvo-Lobo, Rosa Martínez-Piédrola, Laura Cristina Luna-Oliva, Francisco Molina-Rueda 